\title{
Prognostic significance of circulating tumor cells in esophageal carcinoma: a meta-analysis
}

This article was published in the following Dove Press journal:

OncoTargets and Therapy

31 March 2016

Number of times this article has been viewed

\author{
Guang-Lei Qiao' \\ Wei-Xiang $\mathbf{Q i}^{2}$ \\ Wei-Hua Jiang' \\ Ying Chen' \\ Li-Jun $\mathrm{Ma}^{\prime}$
}

'Department of Oncology, Tongren Hospital, Shanghai Jiao Tong University School of Medicine, ${ }^{2}$ Department of Radiation Oncology, Shanghai Proton and Heavy Ion Center, Shanghai, People's Republic of China
Correspondence: Li-Jun Ma Department of Oncology, Tongren Hospital, I I I I, XianXia Road, Shanghai, 200336, People's Republic of China Tel $+8621 \quad 18121226769$

Fax $+8621 \quad 18121226769$

Email626595330@qq.com
Purpose: The prognostic significance of circulating tumor cells (CTCs) in esophageal carcinoma (EC) is controversial. We aim to assess its association with clinicopathological and prognostic relevance in EC by using a meta-analysis.

Methods: We searched PubMed, Cochrane Database, Embase databases, and the references in relevant studies that assessed the clinicopathological or prognostic relevance of CTCs in peripheral blood of patients with EC. Statistical analyses were conducted by using Stata software to calculate the pooled odds ratio (OR), hazard ratio (HR), and 95\% confidence intervals (CIs) using fixed or random-effects models according to the heterogeneity of included studies. The subgroup analyses were performed according to ethnicity, histological type, and detection method.

Results: Sixteen trials containing 1,260 patients were included for analysis. Pooled results showed that presence of CTCs was significantly associated with poor overall survival ( $\mathrm{HR}=1.71$, 95\% CI [1.30, 2.12], $P<0.001)$ and progression-free survival (HR $=1.67,95 \%$ CI [1.19, 2.15], $P<0.001)$ in EC patients. Subgroup analysis indicated that presence of CTCs was closely associated with worse overall survival (Asian: $\mathrm{HR}=1.66,95 \% \mathrm{CI}[1.24,2.08], P<0.001$; squamous cell carcinoma [SCC]: $\mathrm{HR}=1.66,95 \% \mathrm{CI}[1.24,2.08], P<0.001$; no polymerase chain reaction [PCR]: HR $=2.08,95 \%$ CI $[1.40,2.76], P<0.001$ ) and progression-free survival (Asian: $\mathrm{HR}=1.63,95 \%$ CI $[1.15,2.12], P<0.001$; SCC: HR $=1.63,95 \%$ CI $[1.15,2.12], P<0.001$; PCR: $\mathrm{HR}=1.63,95 \% \mathrm{CI}[1.15,2.12], P<0.001)$. Additionally, ORs showed that presence of CTCs was significantly correlated with tumor node metastasis (TNM) staging (overall: OR = 1.96, 95\% CI [1.34, 2.87], $P=0.001$; Asian: OR $=2.09,95 \%$ CI $[1.37,3.19], P=0.001$; SCC: $\mathrm{OR}=1.97,95 \%$ CI $[1.21,3.07], P=0.003$; PCR: OR $=2.23,95 \%$ CI $[1.43,3.47], P<0.001)$, venous invasion (overall: $\mathrm{OR}=2.23,95 \% \mathrm{CI}[1.46,3.40], P<0.001 ;$ Asian: $\mathrm{OR}=2.23,95 \% \mathrm{CI}$ [1.46, 3.40], $P<0.001$; SCC: OR $=2.23,95 \%$ CI [1.46, 3.40], $P<0.001$; PCR: OR $=2.23,95 \%$ CI [1.46, 3.40], $P<0.001$ ), lymph node metastasis (overall: $\mathrm{OR}=2.41,95 \% \mathrm{CI}[1.50,3.86]$, $P<0.001$; Asian: OR $=2.89,95 \%$ CI $[1.80,4.65], P<0.001$; SCC: OR $=2.44,95 \%$ CI $[1.47$, 4.07], $P=0.001$; PCR: OR $=2.89,95 \%$ CI [1.80, 4.65], $P<0.001$ ) and distant metastasis (Asian: $\mathrm{OR}=2.68,95 \% \mathrm{CI}[1.01,7.08], P=0.047)$ in patients with EC.

Conclusion: The presence of CTCs indicates a poor prognosis in EC patients, especially in Asian and SCC patients. Further well-designed prospective studies are recommended to explore the clinical applications of CTCs in patients with EC.

Keywords: CTCs, esophageal carcinoma, metastasis, Asian, prognosis, meta-analysis

\section{Introduction}

Esophageal carcinoma (EC) is the eighth most common cancer and the sixth leading cause of cancer-related death worldwide. ${ }^{1}$ Despite recent progress in diagnostic procedures and multimodality treatment approach, the prognosis of EC patients remains dismal, with 5-year overall survival (OS) rate $<20 \% .^{2,3}$ Recurrence and distant metastases are the main cause of treatment failure and cancer-related deaths. In recent 
years, many studies have demonstrated that circulating tumor cells (CTCs) are related to tumor relapse, metastasis, and patients' prognosis. ${ }^{4-6}$ In EC patients, detecting CTCs may show clinical benefits in treatment and prognosis.

CTCs are tumor cells that are derived from the primary tumor, releasing into the bloodstream and circulating throughout the body. CTCs may form micrometastase, which is an important initial step leading to recurrence and distant metastases. ${ }^{7,8}$ Currently, various new CTCs assays have been developed and used for their detection, including immunocytochemistry, reverse-transcriptase polymerase chain reaction (RT-PCR), and the CellSearch System. ${ }^{6,9,10}$ Several meta-analyses have demonstrated the prognostic significance of CTCs in breast, gastric, and colorectal cancer. 5,11,12 However, there still remains controversy regarding the association between CTCs status and clinical significance in EC. Therefore, we performed a meta-analysis to determine the association between CTCs status and clinicopathological characteristics and prognosis, including tumor stage, lymph node metastasis, distant metastasis, and patients' survival.

\section{Materials and methods}

\section{Search strategy}

A literature search for relevant studies was performed systematically by two researchers (up to October 2015). We searched PubMed, Cochrane Database, and Embase databases using the following search terms: circulating tumor cells, CTCs, and esophageal carcinoma. Moreover, we screened the references of the relevant studies (reviews and included studies) to check for potentially relevant articles. For studies with the same population, only the latest published was selected. The search was restricted to articles in English.

\section{Inclusion criteria}

To keep our analysis accurate and reliable, eligible studies were selected according to the following criteria: 1) patients were pathologically confirmed of EC; 2) immunocytochemistry, RT-PCR, or CellSearch detection methods were used to detect tumor specific genes/antigens in peripheral blood (PB); and 3) investigated the association between clinicopathological or prognostic significance and presence of CTCs in EC patients, with at least one of the outcome measures of interest reported in the study or calculable from the published data.

\section{Exclusion criteria}

Studies were excluded from the meta-analysis if: 1) were review articles or letters; 2) the samples came from the bone marrow, lymph nodes, and mesenteric/portal blood; 3) the results of interest were not reported or it was impossible to calculate results from the original data; 4) studies with fewer than 20 analyzed patients.

\section{Data extraction}

The following data were independently extracted from included studies by two reviewers: author's name, patient's country, publication year, characteristics of the study population (number, age), tumor stage, methods of CTC detection, target antigen and gene, detection rate, sampling time (baseline: the time before operation or chemoradiotherapy), cut-off point, treatment, follow-up period, prognostic outcomes (OS, progression-free survival [PFS]). Disagreements were resolved by discussion between the two reviewers.

\section{Statistical analysis}

The estimated odds ratio (OR) was used to summarize the association between the presence of CTCs and the clinicopathological characteristics of EC. The hazard ratio (HR) was used to summarize the effect measures for the prognostic outcomes (OS, PFS). If the HR and its variance were not reported directly in the original study, these values were calculated from available reported data using software designed by Tierney et al. ${ }^{13}$ The subgroup analyses were performed on the basis of ethnicity (Asian and European), histological type (squamous cell carcinoma [SCC] and adenocarcinoma) and detection method (PCR and no PCR). All statistical values were reported with $95 \%$ confidence intervals (CIs) and the two-sided $P$-value threshold for statistical significance was set at 0.05 . Heterogeneity among the studies was calculated with the Q test and $I^{2}$ statistic, and the $I^{2}$ value indicated the degree of heterogeneity. A $P$-value $<0.10$ or $I^{2}>50 \%$ were considered significant heterogeneity, and a random-effects model (DerSimonian and Laird) was used. Otherwise, a fixed-effects model (Mantel-Haenszel) was used. Subgroup analysis was performed on the basis of ethnicity. Publication bias was assessed by Egger's test and Begg's test. One-way sensitivity analyses were performed to access the stability of the meta-analysis results. All statistical analyses were performed with STATA 12.0 (StataCorp, College Station, TX, USA), using two-sided $P$-values.

\section{Results}

\section{Baseline study characteristics}

We identified 116 studies in this systematic literature search. By screening the titles and abstracts, 71 potential studies 
were retrieved. Then, 55 studies were excluded after they were fully reviewed because they were irrelevant (45 studies) or had insufficient data (ten studies). Finally, 16 articles met the inclusion criteria for analysis, comprising 1,260 patients (Figure 1). ${ }^{14-29}$ The studies were from Asia and Europe (China, Japan, Germany, and Czech) and were published between 2002 and 2015. Eight studies provided HRs on OS and PFS to perform the meta-analysis. The main characteristics of the included studies are summarized in Table 1.

\section{Effect of the presence of CTCs on the prognostic effect (OS and PFS)}

Survival analysis was performed on HR for OS and PFS in six (691 patients) and five (571 patients) studies, respectively. The pooled HR showed that the presence of CTCs was highly correlated with poor OS (HR $=1.71,95 \%$ CI [1.30, 2.12], $P<0.001$, fixed-effect) (Figure 2). Moreover, the presence of CTCs indicated a poor prognostic effect on PFS (HR $=1.67,95 \%$ CI $[1.19,2.15], P<0.001$, fixed-effect) (Figure 3).

In the subgroup analysis, the significant prognostic effect of CTC detection was confirmed in Asian (OS: HR $=1.66,95 \%$ CI $[1.24,2.08], P<0.001$, fixed-effect; PFS: HR $=1.63,95 \%$ CI $[1.15,2.12], P<0.001$, fixed-effect) (Figures 2 and 3), SCC (OS: HR $=1.66,95 \%$ CI [1.24, 2.08], $P<0.001$, fixed-effect; PFS: $\mathrm{HR}=1.63,95 \%$ CI $[1.15,2.12]$, $P<0.001$, fixed-effect); PCR (PFS: HR $=1.63,95 \%$ CI [1.15, 2.12], $P<0.001$, fixed-effect) and no PCR subgroups (OS: HR $=2.08,95 \%$ CI $[1.40,2.76], P<0.001$, fixed-effect) (Table 2).

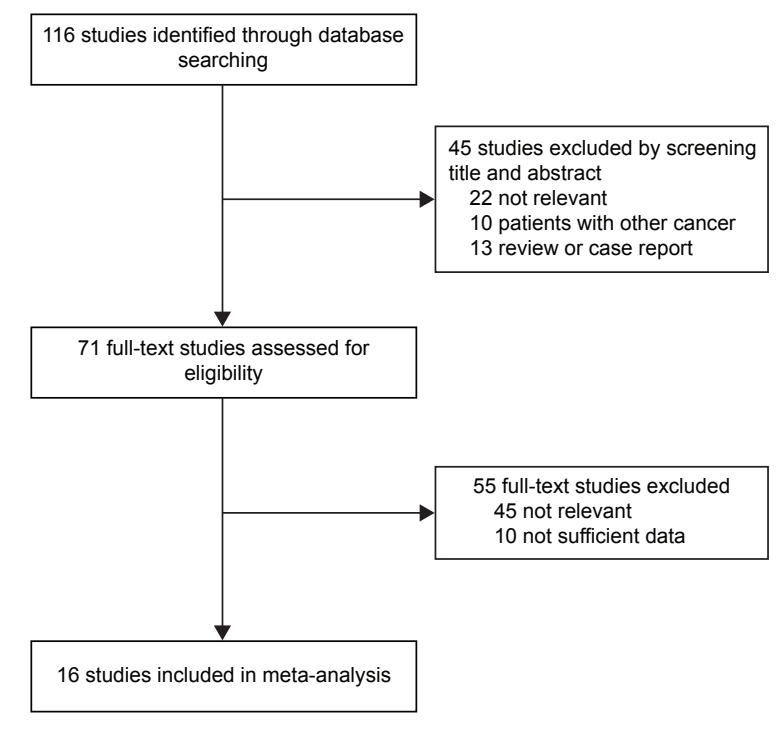

Figure I Flow chart of selecting the eligible publications.

\section{Correlation of CTCs with} clinicopathological features

Correlation of CTCs with the tumor node metastasis (TNM) stage

The meta-analysis on TNM stage indicated a significantly higher incidence of CTCs in the stage III/IV group relative to the stage $\mathrm{I} / \mathrm{II}$ group $(\mathrm{OR}=1.96,95 \% \mathrm{CI}[1.34,2.87], P=0.001$, random-effect). In the subgroup analysis, the incidence of CTCs was significantly different between III/IV and I/II group in Asian (OR $=2.09,95 \%$ CI $[1.37,3.19], P=0.001$, random-effect), SCC (OR $=1.97,95 \%$ CI [1.21, 3.07], $P=0.003$, random-effect), and PCR subgroups ( $\mathrm{OR}=2.23$, 95\% CI [1.43, 3.47], $P<0.001$, random-effect) (Table 2).

The pooled analyses on the depth of invasion (pathology tumor category), lymph node metastasis, and distant metastasis were performed separately. The presence of CTCs in pT3/ $\mathrm{T} 4$ group was significantly higher than $\mathrm{pT} 1 / \mathrm{T} 2$ group (overall: $\mathrm{OR}=1.77,95 \% \mathrm{CI}[1.02,3.06], P=0.04 ; \mathrm{SCC}: \mathrm{OR}=2.14$, 95\% CI [1.56, 2.94], $P<0.001$, random-effect) (Table 2). We also found that the presence of CTCs was associated with a significantly increased risk of lymph node metastasis (overall: $\mathrm{OR}=2.41,95 \% \mathrm{CI}[1.50,3.86], P<0.001$; Asian: $\mathrm{OR}=2.89,95 \% \mathrm{CI}[1.80,4.65], P<0.001$; SCC: $\mathrm{OR}=2.44$, 95\% CI [1.47, 4.07], $P=0.001$; PCR: OR $=2.89,95 \% \mathrm{CI}$ $[1.80,4.65], P<0.001$, random-effect) (Table 2). Moreover, we found that the presence of CTCs was correlated with distant metastasis in Asian subgroup (Asian: $\mathrm{OR}=2.68,95 \%$ CI [1.01, 7.08], $P=0.047$, random-effect) (Table 2).

\section{Correlation of CTCs with histological differentiation}

Eight studies were available for investigating the relationship between CTC status and histological differentiation (poor vs well and moderate). The presence of CTCs was not associated with histological differentiation in overall and subgroup analysis (Table 2).

\section{Correlation of CTCs with venous invasion}

Five studies assessed the relationship between CTC status and venous invasion. We found that the presence of CTCs was correlated with a significantly increased risk of venous invasion in Asian, SCC, and PCR subgroups (overall: $\mathrm{OR}=2.23,95 \% \mathrm{CI}[1.46,3.40], P<0.001$; Asian: $\mathrm{OR}=2.23$, $95 \%$ CI $[1.46,3.40], P<0.001$; SCC: OR $=2.23,95 \%$ CI [1.46, 3.40], $P<0.001 ; \mathrm{PCR}: \mathrm{OR}=2.23,95 \%$ CI [1.46, 3.40], $P<0.001$, fixed-effect) (Table 2).

\section{Publication bias and sensitivity analyses}

We performed Begg's test and Egger's test to assess the publication bias. There was no evidence of publication bias 


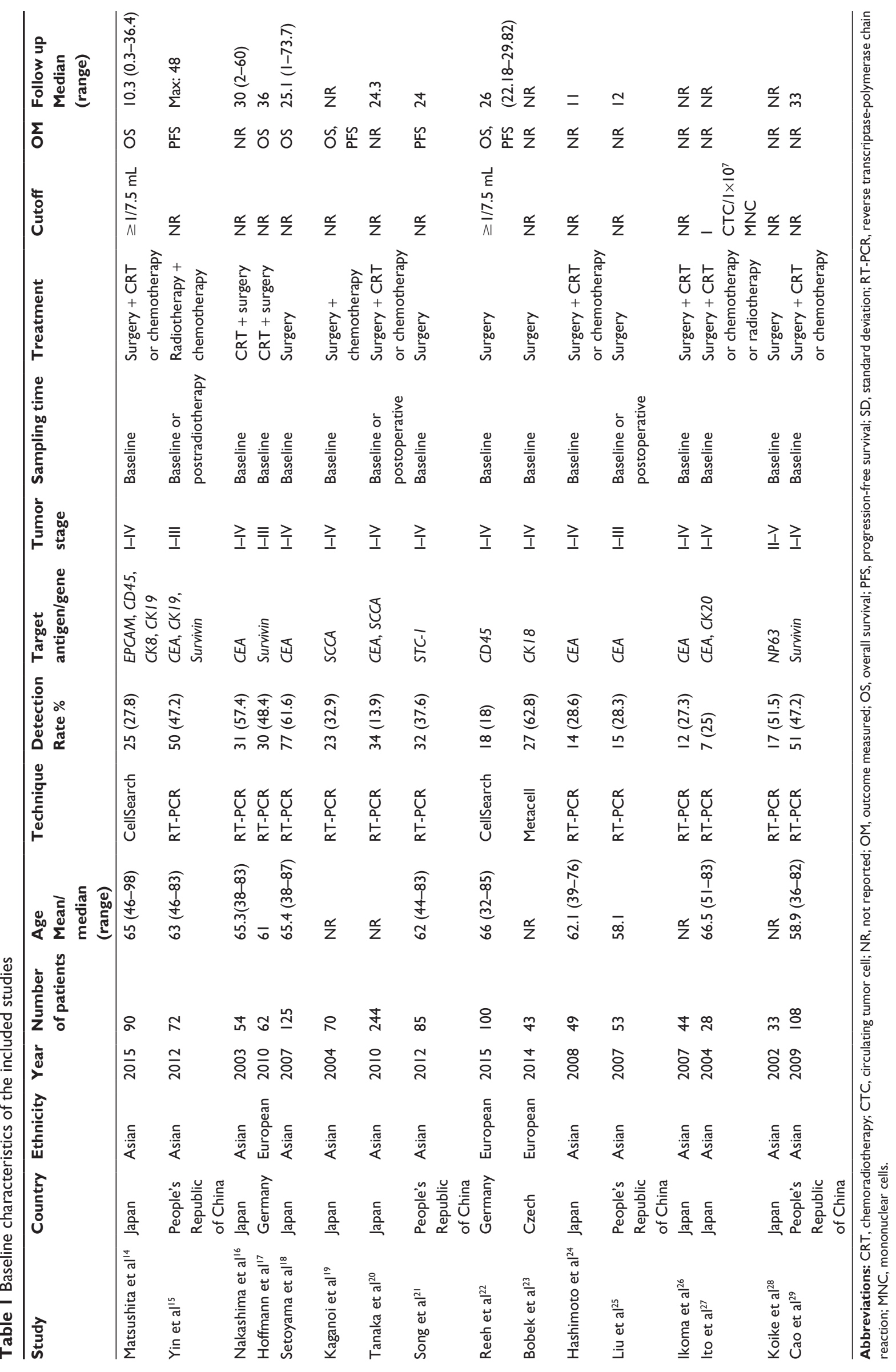




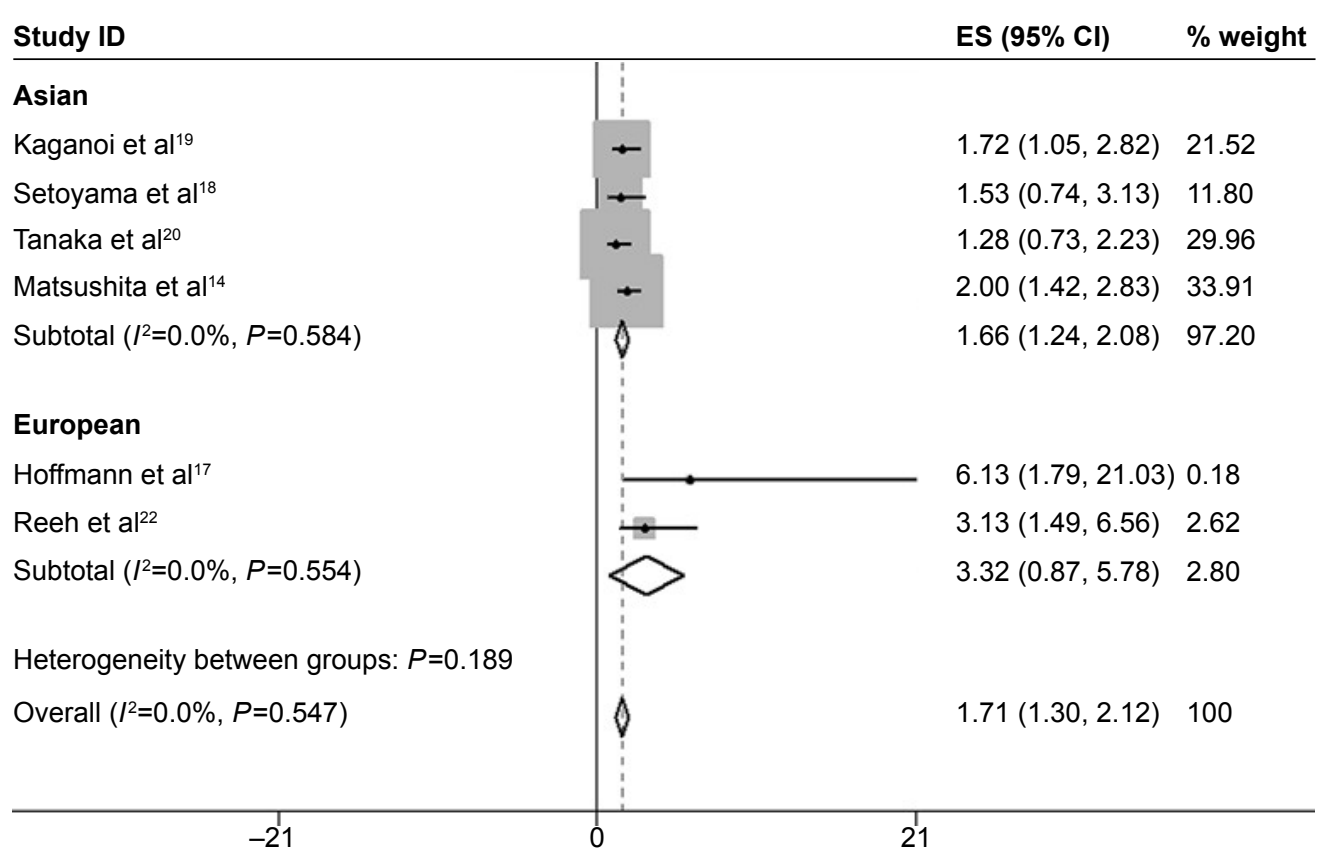

Figure 2 Meta-analysis of HR for the correlation of the presence of CTCs with OS.

Notes: The diamond represents the comprehensive results. The square represents the point estimates. The dotted line represents HR=I.7I.

Abbreviations: $\mathrm{Cl}$, confidence interval; CTCs, circulating tumor cells; HR, hazard ratio; OS, overall survival; ES, effect size.

for the pooled analysis of OS $\left(P_{\text {Begg }}=0.452\right.$ [Figure 4A], $\left.P_{\text {Egger }}=0.375\right)$ and PFS $\left(P_{\text {Begg }}=0.221\right.$ [Figure 4B], $\left.P_{\text {Egger }}=0.200\right)$. We conducted a sensitivity analysis to assess the stability of this meta-analysis. When any single study was deleted, the results were not materially altered (data not shown). These data suggest that our results were stable and credible.

\section{Discussion}

Due to recurrence and metastasis of EC, the 5-year survival rate range remains from $15 \%$ to $20 \%$, despite improvements having been made in esophagectomy and chemoradiotherapy. ${ }^{30-32}$ The detailed mechanisms of EC metastasis have not yet been clarified. Recently, it has been demonstrated that CTCs have the abilities to intravasate

\begin{tabular}{|c|c|c|c|}
\hline Study ID & & ES $(95 \% \mathrm{Cl})$ & $\%$ weight \\
\hline Asian & & & \\
\hline Kaganoi et al ${ }^{19}$ & + & $1.96(1.19,3.22)$ & 22.75 \\
\hline Tanaka et $\mathrm{al}^{20}$ & + & $1.46(0.98,2.17)$ & 66.19 \\
\hline Yin et $a^{15}$ & $\longrightarrow$ & $2.51(0.72,8.73)$ & 1.46 \\
\hline Song et $\mathrm{al}^{21}$ & $\rightarrow$ & $1.95(0.90,4.22)$ & 8.50 \\
\hline Subtotal $\left(I^{2}=0.0 \%, P=0.790\right)$ & 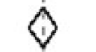 & $1.63(1.15,2.12)$ & 98.90 \\
\hline European & & & \\
\hline Reeh et $a^{22}$ & & $5.06(2.23,11.48)$ & 1.10 \\
\hline Subtotal $\left(I^{2}=. \%, P=.\right)$ & & $5.06(0.44,9.68)$ & 1.10 \\
\hline Heterogeneity between group & & & \\
\hline Overall $\left(I^{2}=0.0 \%, P=0.536\right)$ & (1) & $1.67(1.19,2.15)$ & 100 \\
\hline
\end{tabular}

Figure 3 Meta-analysis of HR for the correlation of the presence of CTCs with PFS.

Notes: The diamond represents the comprehensive results. The square represents the point estimates. The dotted line represents HR=I.67. $P$ value in the European study is missing as there is only one study.

Abbreviations: $\mathrm{Cl}$, confidence interval; CTCs, circulating tumor cells; HR, hazard ratio; PFS, progression-free survival; ES, effect size. 


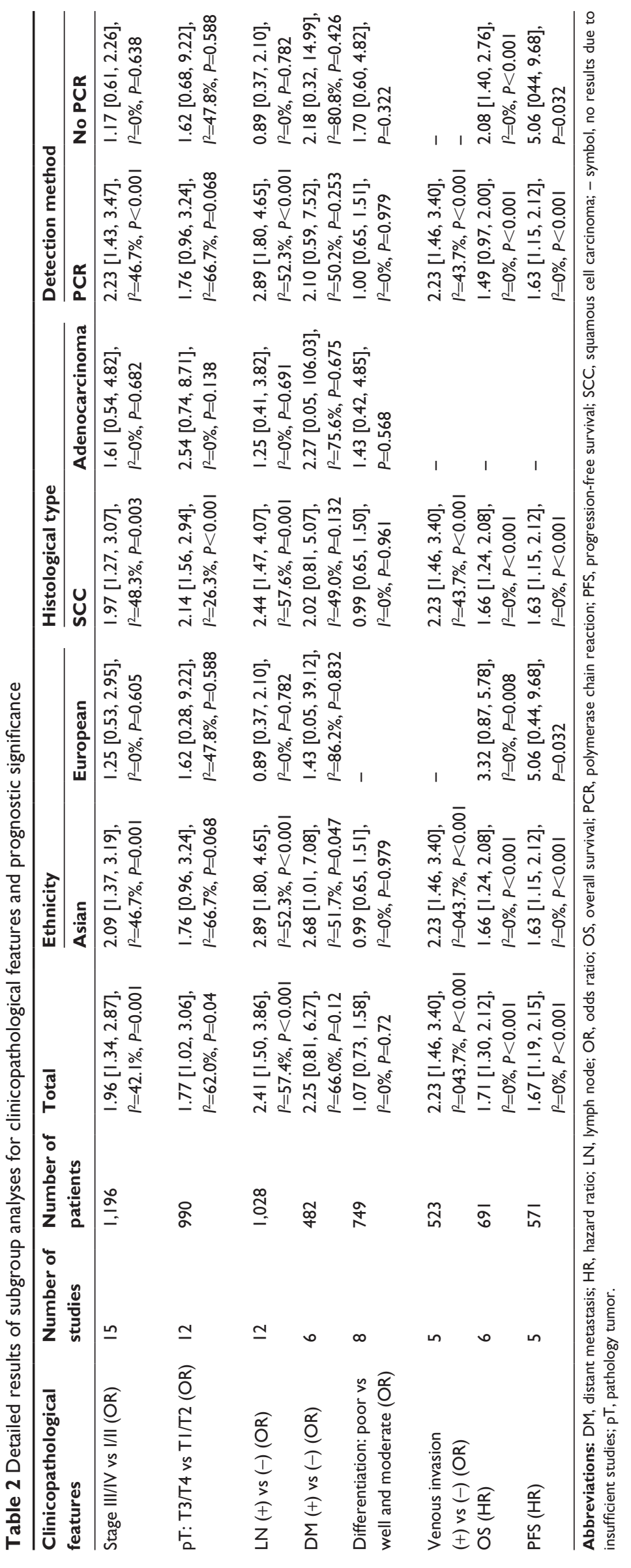


A Begg's funnel plot with pseudo $95 \%$ confidence limits

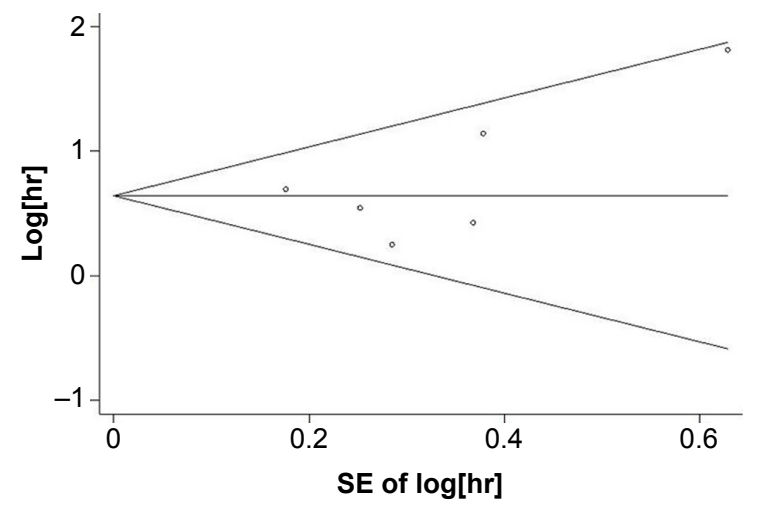

B Begg's funnel plot with pseudo $95 \%$ confidence limits

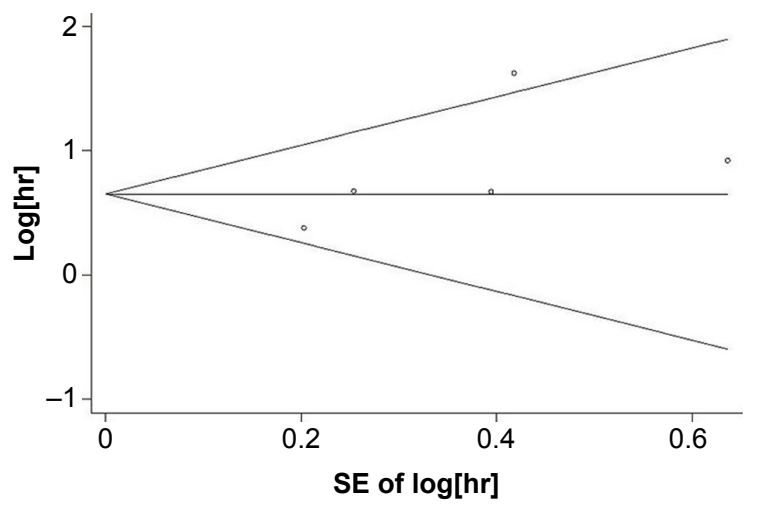

Figure 4 Funnel plot analysis (A: OS; B: PFS).

Abbreviations: OS, overall survival; PFS, progression-free survival; SE, standard error.

into the circulation, reach the distant organs, evade immune system, and eventually grow into clinically detectable metastasis. ${ }^{33-35}$ Several studies have indicated that the presence of CTCs could be significantly correlated with distant metastasis and poor prognosis in lung cancer ${ }^{36}$ and colorectal cancer. ${ }^{6}$ The presence of CTCs may explain the mechanism of metastasis and relapse by the "seed and soil theory" in colorectal cancer. ${ }^{37}$ However, the relationships between presence of CTCs and clinical outcomes in EC patients are not clear. Therefore, a quantitative meta-analysis about the correlations is required. This is the first meta-analysis to evaluate the clinicopathological and prognostic significance of CTCs detection by summarizing all relevant studies.

Our meta-analysis indicates that the presence of CTCs is significantly associated with TNM staging, venous invasion, lymph node metastasis in Asian, SCC, and PCR subgroups. In addition, the Asian population with presence of CTCs is positively correlated with distant metastasis. The Paget's "seed and soil hypothesis" claims that the metastasis forms when certain tumor cells (seed) are compatible with microenvironment of certain organs (soil). ${ }^{37,38}$ The CTCs are shed from the primary tumor, form micrometastatic foci via hematogenous metastasis and eventually develop into distant metastasis. ${ }^{37,39}$ This may be one of the mechanisms of metastasis of EC.

The survival analysis reveals that patients with presence of CTCs have worse OS and PFS than those who lack CTCs. We also performed subgroup analyses based on ethnicity, histological type, detection method to further evaluate prognostic value of CTCs. The results suggested that patients with presence of CTCs have poor OS and PFS in Asian and SCC subgroups. This may be attributed to the differences in gene and environment among ethnicity. Several genes have been found to contribute to esophageal squamous cell carcinoma in Asian population, such as ADH1B, ALDH2, PLCE1, and C20orf54. ${ }^{40,41}$ Moreover, nutritional imbalance, nitrosamine-rich and mycotoxin contaminated foods can play important roles in EC among Asian population. ${ }^{42}$ The absence of publication bias is confirmed with the funnel plots. These results are consistent with prior reports of meta-analysis in lung cancer, ${ }^{36}$ colorectal cancer, ${ }^{6}$ and gastric cancer. ${ }^{5}$ Thus, we prove that the presence of CTCs at baseline in PB is significantly correlated with tumor metastasis and poor prognosis of Asian patients with EC.

The CTCs are defined as tumor cells originating from primary tumor and circulating freely in PB. Previous studies showed that the CTCs had detached from primary tumor before tumor metastasis was clinically visible. ${ }^{43}$ Moreover, detection of CTCs in PB is very convenient and comfortable for patients, and is readily repeatable in a noninvasive manner. Thus, the presence of CTCs in PB could be used as a monitoring tool for tumor metastasis and prognosis of EC.

There are limitations to this meta-analysis. First, several articles did not provide the HRs and 95\% CIs, and we calculated them from the reported data. Second, there are varied methods of detecting CTCs in the included studies and different end points and experimental design could have partly affected the results of survival analyses. Third, the heterogeneity could not be eliminated, and we used the random-effects model to obtain more conservative estimates. This heterogeneity may have been caused by differences in population characteristics. Furthermore, we should note that the enrolled studies were both cohort studies and nonrandomized clinical trials, and this difference in experimental design may also have caused heterogeneity. Despite these limitations, our meta-analysis is the first article to analyze the clinical significance and prognostic value of presence of CTCs in EC. 
In conclusion, our meta-analysis indicates that presence of CTCs is significantly associated with poor prognosis in EC patients, especially in Asian and SCC patients. Moreover, presence of CTCs is positively correlated with TNM staging, venous invasion and lymph node metastasis in Asian and SCC patients, and with distant metastasis in Asian patients. These results should be confirmed by adequate, high-quality, well-designed multicenter studies.

\section{Acknowledgments}

This work was supported by Science and Technology Commission of Shanghai Municipality (No 13ZR1430800) and Shanghai Municipal Commission of Health and Family Planning (No 20114194).

\section{Disclosure}

The authors report no conflicts of interest in this work.

\section{References}

1. Jemal A, Bray F, Center MM, Ferlay J, Ward E, Forman D. Global cancer statistics. CA Cancer J Clin. 2011;61(2):69-90.

2. Kim T, Grobmyer SR, Smith R, et al. Esophageal cancer - the five year survivors. J Surg Oncol. 2011;103(2):179-183.

3. Ferlay J, Shin HR, Bray F, Forman D, Mathers C, Parkin DM. Estimates of worldwide burden of cancer in 2008: GLOBOCAN 2008. Int J Cancer. 2010;127(12):2893-2917.

4. Wang Z, Cui K, Xue Y, Tong F, Li S. Prognostic value of circulating tumor cells in patients with squamous cell carcinoma of the head and neck: a systematic review and meta-analysis. Med Oncol. 2015; 32(5):164.

5. Huang X, Gao P, Sun J, et al. Clinicopathological and prognostic significance of circulating tumor cells in patients with gastric cancer: a meta-analysis. Int J Cancer. 2015;136(1):21-33.

6. Huang X, Gao P, Song Y, et al. Meta-analysis of the prognostic value of circulating tumor cells detected with the CellSearch System in colorectal cancer. BMC Cancer. 2015;15:202.

7. Pantel K, Alix-Panabieres C. Circulating tumour cells in cancer patients: challenges and perspectives. Trends Mol Med. 2010;16(9):398-406.

8. Iinuma H, Watanabe T, Mimori K, et al. Clinical significance of circulating tumor cells, including cancer stem-like cells, in peripheral blood for recurrence and prognosis in patients with Dukes' stage B and C colorectal cancer. J Clin Oncol. 2011;29(12):1547-1555.

9. Fetsch PA, Cowan KH, Weng DE, Freifield A, Filie AC, Abati A. Detection of circulating tumor cells and micrometastases in stage II, III, and IV breast cancer patients utilizing cytology and immunocytochemistry. Diagn Cytopathol. 2000;22(5):323-328.

10. Lambrechts AC, Bosma AJ, Klaver SG, et al. Comparison of immunocytochemistry, reverse transcriptase polymerase chain reaction, and nucleic acid sequence-based amplification for the detection of circulating breast cancer cells. Breast Cancer Res Treat. 1999;56(3):219-231.

11. Fei F, Du Y, Di G, Wu J, Shao Z. Are changes in circulating tumor cell (CTC) count associated with the response to neoadjuvant chemotherapy in local advanced breast cancer? A meta-analysis. Oncol Res Treat. 2014; 37(5):250-254.

12. Sloothaak DA, Sahami S, van der Zaag-Loonen HJ, et al. The prognostic value of micrometastases and isolated tumour cells in histologically negative lymph nodes of patients with colorectal cancer: a systematic review and meta-analysis. Eur J Surg Oncol. 2014;40(3): 263-269.
13. Tierney JF, Stewart LA, Ghersi D, Burdett S, Sydes MR. Practical methods for incorporating summary time-to-event data into metaanalysis. Trials. 2007;8:16.

14. Matsushita D, Uenosono Y, Arigami T, et al. Clinical significance of circulating tumor cells in peripheral blood of patients with esophageal squamous cell carcinoma. Ann Surg Oncol. 2015;22:3674-3680.

15. Yin XD, Yuan X, Xue JJ, Wang R, Zhang ZR, Tong JD. Clinical significance of carcinoembryonic antigen-, cytokeratin 19-, or survivin-positive circulating tumor cells in the peripheral blood of esophageal squamous cell carcinoma patients treated with radiotherapy. Dis Esophagus. 2012;25(8):750-756.

16. Nakashima S, Natsugoe S, Matsumoto $M$, et al. Clinical significance of circulating tumor cells in blood by molecular detection and tumor markers in esophageal cancer. Surgery. 2003;133(2):162-169.

17. Hoffmann AC, Vallbohmer D, Grimminger P, et al. Preoperative survivin mRNA detection in peripheral blood is an independent predictor of outcome in esophageal carcinoma. Pharmacogenomics. 2010;11(3): 341-347.

18. Setoyama T, Natsugoe S, Okumura H, Matsumoto M, Uchikado Y, Aikou T. Isolated tumour cells in blood and E-cadherin expression in oesophageal squamous cell cancer. Br J Surg. 2007;94(8):984-991.

19. Kaganoi J, Shimada Y, Kano M, Okumura T, Watanabe G, Imamura M. Detection of circulating oesophageal squamous cancer cells in peripheral blood and its impact on prognosis. Br J Surg. 2004;91(8):1055-1060.

20. Tanaka K, Yano M, Motoori M, et al. CEA-antigen and SCC-antigen mRNA expression in peripheral blood predict hematogenous recurrence after resection in patients with esophageal cancer. Ann Surg Oncol. 2010; 17(10):2779-2786.

21. Song H, Xu B, Yi J. Clinical significance of stanniocalcin-1 detected in peripheral blood and bone marrow of esophageal squamous cell carcinoma patients. J Exp Clin Cancer Res. 2012;31:35.

22. Reeh M, Effenberger KE, Koenig AM, et al. Circulating tumor cells as a biomarker for preoperative prognostic staging in patients with esophageal cancer. Ann Surg. 2015;261(6):1124-1130.

23. Bobek V, Matkowski R, Gurlich R, et al. Cultivation of circulating tumor cells in esophageal cancer. Folia Histochem Cytobiol. 2014;52(3): 171-177.

24. Hashimoto T, Kajiyama Y, Tsutsumi-Ishii Y, Nagaoka I, Tsurumaru M. Circulating micrometastases of esophageal cancer detected by carcinoembryonic antigen $\mathrm{mRNA}$ reverse transcriptase-polymerase chain reaction: clinical implications. Dis Esophagus. 2008;21(8):690-696.

25. Liu Z, Jiang M, Zhao J, Ju H. Circulating tumor cells in perioperative esophageal cancer patients: quantitative assay system and potential clinical utility. Clin Cancer Res. 2007;13(10):2992-2997.

26. Ikoma D, Ichikawa D, Ueda Y, et al. Circulating tumor cells and aberrant methylation as tumor markers in patients with esophageal cancer. Anticancer Res. 2007;27(1B):535-539.

27. Ito $H$, Kanda $T$, Nishimaki $T$, Sato H, Nakagawa S, Hatakeyama K. Detection and quantification of circulating tumor cells in patients with esophageal cancer by real-time polymerase chain reaction. J Exp Clin Cancer Res. 2004;23(3):455-464

28. Koike M, Hibi K, Kasai Y, Ito K, Akiyama S, Nakao A. Molecular detection of circulating esophageal squamous cell cancer cells in the peripheral blood. Clin Cancer Res. 2002;8(9):2879-2882.

29. Cao M, Yie SM, Wu SM, et al. Detection of survivin-expressing circulating cancer cells in the peripheral blood of patients with esophageal squamous cell carcinoma and its clinical significance. Clin Exp Metastasis. 2009;26(7):751-758.

30. Enzinger PC, Mayer RJ. Esophageal cancer. NEngl J Med. 2003;349(23): 2241-2252.

31. Zhang Y. Epidemiology of esophageal cancer. World J Gastroenterol. 2013;19(34):5598-5606.

32. Pennathur A, Gibson MK, Jobe BA, Luketich JD. Oesophageal carcinoma. Lancet. 2013;381(9864):400-412.

33. Chambers AF, Groom AC, MacDonald IC. Dissemination and growth of cancer cells in metastatic sites. Nat Rev Cancer. 2002;2(8):563-572. 
34. Joosse SA, Gorges TM, Pantel K. Biology, detection, and clinical implications of circulating tumor cells. EMBO Mol Med. 2015; 7(1):1-11.

35. Pantel K, Speicher MR. The biology of circulating tumor cells. Oncogene. Epub 2015 Jun 8.

36. Wang J, Wang K, Xu J, Huang J, Zhang T. Prognostic significance of circulating tumor cells in non-small-cell lung cancer patients: a metaanalysis. PLoS One. 2013;8(11):e78070.

37. Fidler IJ. The pathogenesis of cancer metastasis: the 'seed and soil' hypothesis revisited. Nat Rev Cancer. 2003;3(6):453-458.

38. Ksiazkiewicz M, Markiewicz A, Zaczek AJ. Epithelial-mesenchymal transition: a hallmark in metastasis formation linking circulating tumor cells and cancer stem cells. Pathobiology. 2012;79(4):195-208.

39. Stoecklein NH, Hosch SB, Bezler M, et al. Direct genetic analysis of single disseminated cancer cells for prediction of outcome and therapy selection in esophageal cancer. Cancer Cell. 2008;13(5):441-453.
40. Cui R, Kamatani Y, Takahashi A, et al. Functional variants in ADH1B and ALDH2 coupled with alcohol and smoking synergistically enhance esophageal cancer risk. Gastroenterology. 2009;137(5):1768-1775.

41. Wang LD, Zhou FY, Li XM, et al. Genome-wide association study of esophageal squamous cell carcinoma in Chinese subjects identifies susceptibility loci at PLCE1 and C20orf54. Nat Genet. 2010; 42(9):759-763.

42. Zhang J, Jiang Y, Wu C, et al. Comparison of clinicopathologic features and survival between eastern and western population with esophageal squamous cell carcinoma. J Thorac Dis. 2015;7(10):1780-1786.

43. Stott SL, Lee RJ, Nagrath S, et al. Isolation and characterization of circulating tumor cells from patients with localized and metastatic prostate cancer. Sci Transl Med. 2010;2(25):25ra23.
OncoTargets and Therapy

\section{Publish your work in this journal}

OncoTargets and Therapy is an international, peer-reviewed, open access journal focusing on the pathological basis of all cancers, potential targets for therapy and treatment protocols employed to improve the management of cancer patients. The journal also focuses on the impact of management programs and new therapeutic agents and protocols on

\section{Dovepress}

patient perspectives such as quality of life, adherence and satisfaction. The manuscript management system is completely online and includes a very quick and fair peer-review system, which is all easy to use. Visit http://www.dovepress.com/testimonials.php to read real quotes from published authors. 